\title{
A Pilot Observational Study Comparing Wet Bulb Globe Temperature (WBGT) Parameter Measurements Between Three Commercial Kitchen Configurations
}

\author{
Madison Ellis ${ }^{1}$, Rod Handy ${ }^{1}$, Darrah Sleeth ${ }^{1}$, Leon Pahler ${ }^{1}$, and Camie Schaefer ${ }^{1}$ \\ ${ }^{1}$ University of Utah, Salt Lake City, UT, USA \\ DOI: https://doi.org/10.47611/jsr.v10i1.1181
}

\begin{abstract}
$\underline{\text { ABSTRACT }}$
Line cooks in commercial restaurants work intense, high-stress shifts during near sources of heat, rendering them vulnerable to heat stress and occupational injury. However, there is a dearth of literature on heat stress among this population. This study investigated three common commercial kitchen configurations-zone, island, and assemblyto determine which design experiences the highest temperatures and if temperatures were in excess of recommended levels. A total of 11 restaurants were sampled for temperature using a Wet Bulb Globe Thermometer (WBGT). Descriptive statistics indicated that, on average, zone configurations are hotter than other kitchens and could pose a risk of heat stress; however, a Kruskal-Wallis test of significance revealed that this distinction was not statistically significant. Two measurements for zone kitchens were borderline significant, suggesting that future studies with greater statistical power would find significant differences between the kitchen types and further illuminate the risk of heat stress.
\end{abstract}

\section{Introduction}

The culture of food consumption in America has shifted from at-home preparation of meals to a nearly equal reliance on takeout, dine-in, and delivery food, ${ }^{1}$ and demand for food service workers has escalated in turn. Approximately 2.3 million workers, many of who are minorities, work as cooks in various establishments across the United States, generally as line cooks who are either responsible for the entirety of food preparation or who operate a single "station" inside a kitchen ${ }^{2,3}$ Food service workers, especially the "back room staff" (e.g., cooks, dishwashers), often experience unsafe working conditions in kitchens, ${ }^{3-5}$ and immigrant workers are even more likely to work in unhygienic and crowded environments. ${ }^{6-8}$ Unsafe working conditions are often exacerbated by kitchen design, which is shaped by ergonomics, energy efficiency, ventilation, and ease of maintenance (among other factors). ${ }^{9}$ Oftentimes kitchen design maximizes work capacity rather than worker comfort; rising real estate costs have driven restaurants to maximize table space and subsequently downsizing kitchen areas. ${ }^{10,11}$ These trends tend to place line cooks in cramped conditions near or over sources of heat such as stoves, salamanders (industrial toasters), fryers, and dishwashers for the entirety of an 8-10 hour shift. ${ }^{11-13}$

Anecdotally, cooks report experiencing extreme summer temperatures, dehydration, loss of water weight, and distress due to kitchen temperatures. ${ }^{14}$ Occupational health professionals have recorded that cooks experience high rates of musculoskeletal pain, burns, cuts, and exposure to hazards such poor air quality and or toxic chemicals, which a growing body of evidence has linked to the discomfort and loss of focus associated with heat stress and strain. ${ }^{15-17}$ Acute exposure to excessive heat is associated with numerous other symptoms, ranging from discomfort to headache to syncope to heat stroke, while chronic exposure has been linked to higher rates of renal and thyroid disease, among others. ${ }^{18,19}$ While there is generally a dearth of literature on food service workers and heat stress, a few studies, such 
as those by Gharibi et al. and Singh et al. have identified heat as the source of adverse health effects, including inflammatory responses and changes in hematological parameters, among kitchen workers. ${ }^{20,21}$

The majority of health and safety professionals rely on employee-level interventions such as light clothing, rest breaks, and hydration to control heat stress, and food service is no different. ${ }^{14,22}$ Adequate ventilation can reduce heat exposure, but may lead to uneven temperatures throughout the establishment or present cooking difficulties. ${ }^{23}$ However, different kitchen configurations distribute heat-generating equipment in different configurations throughout the kitchen, oftentimes with the intent of lessening heat exposures for cooks. This study proposes to investigate if temperatures in commercial kitchens reach levels that might result in employee heat stress, and to further determine if one kitchen configuration reaches higher temperatures than others.

\section{Methods}

This observational pilot study was designed to establish preliminary temperature profiles among different kitchen configurations in order to determine if 1) kitchen temperatures reached excessive heat levels (defined by the temperature and work intensity matrix created by the American Conference of Governmental Industrial Hygienists [ACGIH), and 2) if certain kitchen configurations tended towards higher temperatures. The three kitchen configurations investigated in this study are the zone kitchen, island kitchen, and assembly kitchen (see Figures 1-3 for details). Based upon the initial qualitative observations of the three types, it was hypothesized that the zone kitchen layout was likely to demonstrate the highest temperatures, as it does not center its hottest equipment in the middle of the kitchen, therefore concentrating the amount of heat in one specific area and reducing potential heat dispersion.

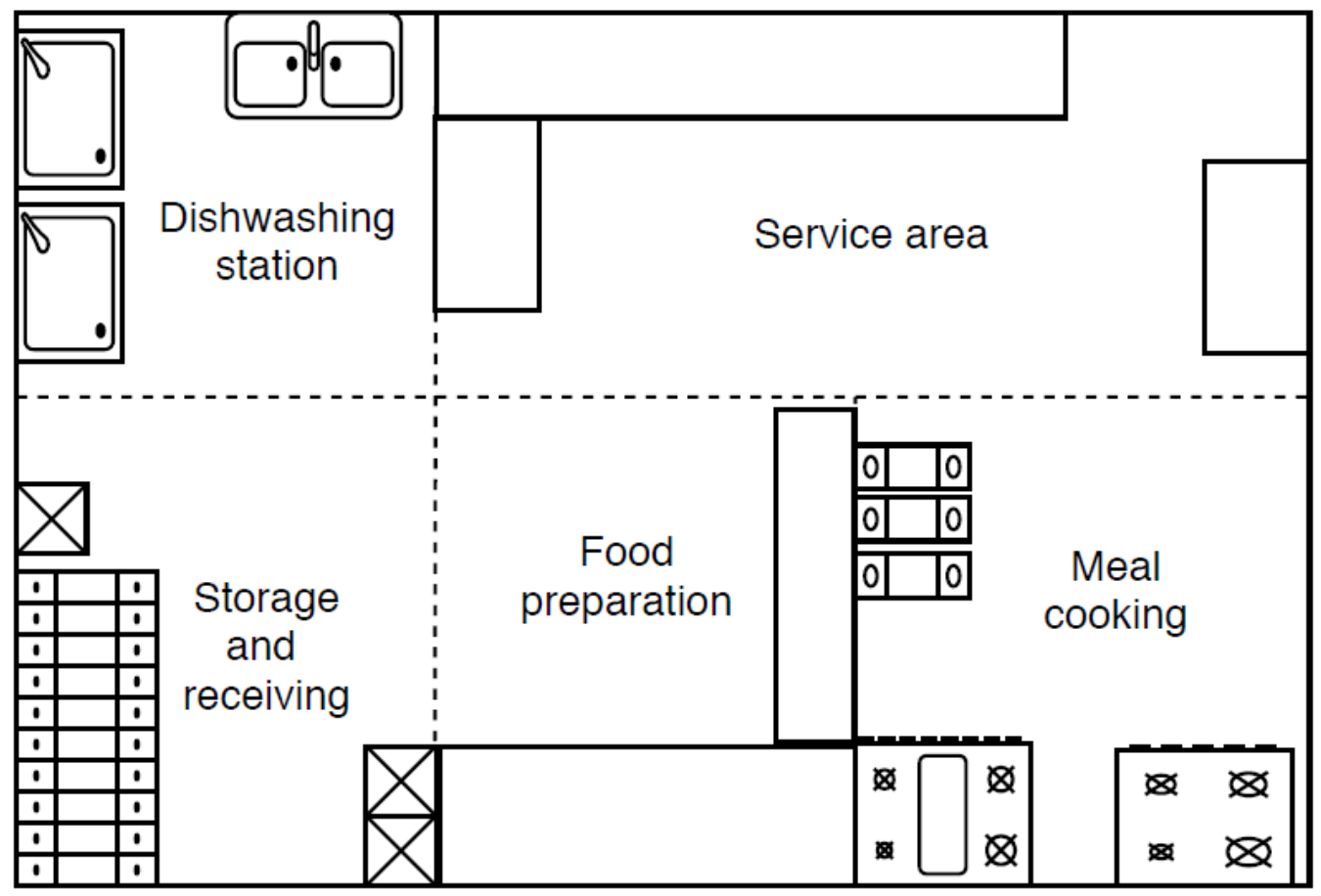

Figure 1. Schematic of a zone kitchen, which places all meal cooking in one area of the kitchen. Zone kitchen configurations are used to increase organization and divide personnel according to their specific tasks, such that one person might spend their entire chef cooking food. This is typically beneficial for restaurants with a large menu selection. ${ }^{9}$ 


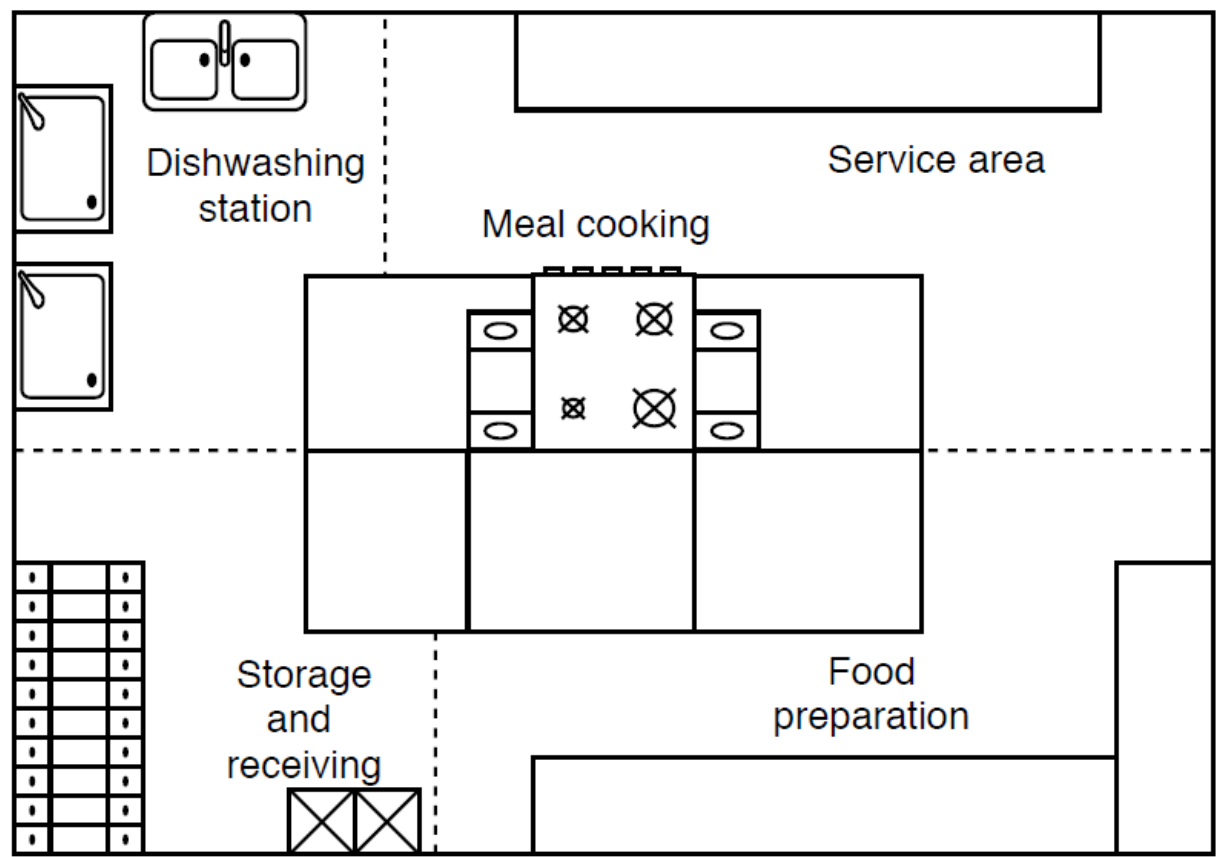

Figure 2. Schematic of an island kitchen, which positions cooking in the center of the kitchen in one large "block." Food preparation takes place along the walls of the kitchen. Island kitchens require greater amounts of space to allow for free flow of preparation and cooking. ${ }^{9}$

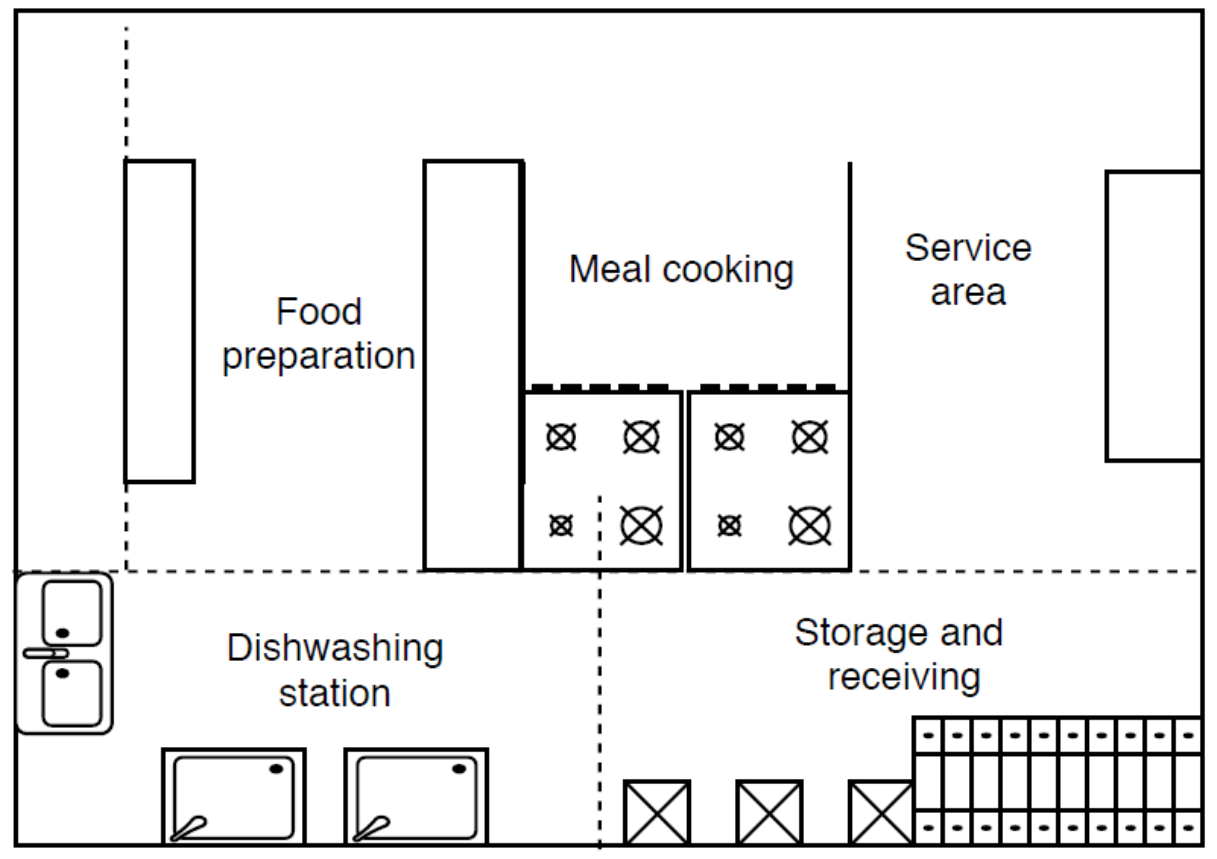

Figure 3. Schematic of an assembly kitchen, which is typically used in fast food or casual dining settings where the limited menu allows for preparation of meals as the customer passes through from food preparation to meal cooking to checkout in the service area. All meal cooking is centralized in the customer-facing portion of the kitchen. ${ }^{9}$ 
Recruitment took place between February 2019 to December 2019, with specific outreach to zone, island, and assembly kitchens. ${ }^{24}$ Most recruitment took place within the Salt Lake City, UT area, although restaurants in Seattle, WA and Boise, ID were also recruited in order to obtain a possible control for differing elevations within different regions. Initially, a cover letter was constructed to send to restaurants explaining the premise of the study and the instrumentation that would be used. Due to low response rates, a researcher then traveled to individual restaurants at off-hour times (e.g., 3 p.m.) and recruited individual managers and employees to participate.

In order to use ACGIH work-rest ratios (see Table 1), a Wet Bulb Globe Thermometer (WBGT) was selected to measure temperatures. The WBGT provides the wet bulb temperature (which takes into account the temperature while also considering evaporation) the dry bulb (ambient air or dry temperature), and globe temperature (radiant heat, which is especially key in measuring heat that would be absorbed from kitchen equipment). Line cooks work continuously with few, if any, break periods, and labor that can be fairly characterized as moderate (sustained moderate hand and arm work) or heavy (walking at a fast pace, intense arm and trunk work). ${ }^{25}$ As previous work by Gharibi et al. characterized baking goods as heavy labor under ACGIH Guidelines, this study chose to do the same, as the tasks are analogous in terms of effort. ${ }^{20}$

Table 1. ACGIH recommended maximum temperature values stratified by work-rest regimens and type of work..$^{25}$

\begin{tabular}{|l|l|l|l|}
\cline { 2 - 4 } \multicolumn{1}{c|}{} & \multicolumn{2}{c|}{ Work load (WBGTi) in $\mathbf{C}^{\circ}$} \\
\hline Work-rest regimens & Light & Moderate & Heavy \\
\hline Continuous work & 30 & 26 & 25 \\
\hline $50 \%$ work, 25\% rest, each hour $50 \%$ rest, each hour & 31 & 27 & 25 \\
\hline $25 \%$ work, 75\% rest, each hour & 31 & 29 & 27 \\
\hline
\end{tabular}

Sampling took place $2 / 27 / 2019$ - 12/26/2019, on a date and time in which the restaurant experienced peak activity and therefore greatest possible temperature levels (e.g., 7 p.m. on a Friday night). Prior to active sampling, a brief survey of the kitchen was taken by the researcher to classify the kitchen configuration and visually observe all heatgenerating appliances in the kitchen. A brief discussion was also had with the line cook on duty to determine where, in his/her opinion, the greatest heat exposures were present. A TSI Quest Temp 32 WBGT $^{\text {тM }}$ (TSI/Quest Technologies, Oconomowoc, Wisconsin) was then placed in the area mutually agreed to be the most central area of heat by both the researcher and the chef/manager of the kitchen.

The WBGT indoor $($ WBGTi $)($ WBGTIndoor $=(0.7 \times$ Temp Wet $)+(0.3 \times$ Temp Globe $)$ is a final measurement of the combination between the wet bulb and dry bulb parameters. This equation is preferential over the WBGT outdoor equation, which considers solar energy radiating from the sun. WBGTi is typically used by industrial hygienists and occupational health and safety professionals to determine acceptable work-rest regimens or break schedules. ${ }^{26}$ Prior to active temperature readings in the kitchen, the WBGT was turned on for 15 minutes within the lobby to acclimate to the surroundings and ensure that readings would be accurate. Inside the kitchen, the WBGT was placed in accordance with the following criteria: a) at least 1.524 meters above the ground, b) on a heat-proof surface, c) central in the area identified as reaching greatest heat concentrations. ${ }^{27}$ The WBGT was always placed at a height that was equivalent to a waist-to-chest height of an average human (i.e., at least waist high or 1.524 meters, whichever was higher).

\section{Statistical Analysis}

Descriptive statistics were calculated in Excel $^{\mathrm{TM}}$ (Microsoft, Redmond, Washington) to determine the average temperatures of each configuration and compare those to ACGIH temperature recommendations for continual heavy labor. An analysis of variance was performed for each of the WBGT's parameters (i.e., dry bulb, wet bulb, globe, and WBGT $_{\text {indoor }}$ ) to determine if one configuration's distribution was statistically significantly different from the others 
$($ alpha $=0.05)$. Following determination of the normality of the data in IH STAT Version 235 (American Industrial Hygiene Association), a non-parametric test-the ANOVA equivalent, Kruskal-Wallis test-was used to assess whether the distributions amongst the WBGT parameters were statistically significantly different from one another.

\section{Results}

A total of $3 / 25$ restaurants responded to the initial inquiry letters (12\% response rate), and 8 responded to in-person recruitment (47\% response rate) for an overall total of 11 restaurants recruited (9 in Salt Lake City, 1 in Seattle, and 1 in Boise). Kitchen configurations were distributed between the total sample size (4 zone kitchens, 3 island kitchens, and 3 assembly kitchens). Descriptive statistics revealed that the group of zone kitchen configurations experienced higher temperatures, with higher average values measured in all four parameters of the WBGT (see Table 2). Overall, WBGTi of 2 of the 3 zone kitchens fell within at least $\pm 1^{\circ} \mathrm{C}$ of ACGIH recommendation for continual heavy work, with one island kitchen meeting that same criteria.

Table 2. Individual and aggregate temperature Results Stratified by Kitchen Configuration. Ambient temperatures obtained from U.S. Climate Data. ${ }^{28} *$ Denotes temperatures within $\pm 1^{\circ} \mathrm{C}$ of ACGIH recommendation for continual heavy work.

\begin{tabular}{|c|c|c|c|c|c|c|}
\hline Kitchen & Sampling Date & $\begin{array}{c}\text { Average High/Low Ambient } \\
\left.\text { Temperature (in } \mathrm{C}^{\circ}\right)\end{array}$ & Wet $\mathrm{C}^{\circ}$ & $\begin{array}{l}\text { Dry } \\
\text { C }^{\circ}\end{array}$ & Globe $\mathbf{C}^{\circ}$ & WBGTi C ${ }^{\circ}$ \\
\hline \multicolumn{3}{|c|}{ Zone (n=4, aggregated) } & 22.8 & 43.9 & 44.7 & $29.1 *$ \\
\hline Zone-1 & $2 / 27 / 19$ & $12.7 / 7.2$ & 33.91 & 89.0 & 84.1 & $48.8 *$ \\
\hline Zone-2 & $6 / 6 / 2019$ & $30.6 / 17.2$ & 17.1 & 26.3 & 27.1 & 19.8 \\
\hline Zone-3 & $7 / 12 / 2019$ & $36.7 / 22.8$ & 20.5 & 26.3 & 28.8 & 22.9 \\
\hline Zone-4 & $10 / 22 / 2019$ & $16.1 / 7.8$ & 19.8 & 34.2 & 37.3 & $24.5^{*}$ \\
\hline \multicolumn{3}{|c|}{ Island ( $=3$, aggregated) } & 15.4 & 24.9 & 26.1 & 18.8 \\
\hline Island-1 & $9 / 22 / 2019$ & $22.2 / 8.9$ & 19.8 & 34.2 & 37.3 & $24.5^{*}$ \\
\hline Island-2 & $12 / 6 / 2019$ & $10.0 / 1.7$ & 15.5 & 24.4 & 24.9 & 19.8 \\
\hline Island-3 & $12 / 26 / 2019$ & $3.3 / 0.6$ & 13.1 & 21.1 & 23.6 & 22.9 \\
\hline \multicolumn{3}{|c|}{ Assembly (n=3, aggregated) } & 16.1 & 24.8 & 27.1 & 19.2 \\
\hline Assembly-1 & $6 / 18 / 2019$ & $26.7 / 15.6$ & 16.8 & 26.2 & 28.3 & 20.2 \\
\hline Assembly-2 & $9 / 16 / 2019$ & $29.4 / 22.8$ & 18.1 & 27.0 & 29.5 & 21.6 \\
\hline Assembly-3 & $10 / 22 / 2019$ & $16.1 / 7.8$ & 14.0 & 22.7 & 24.9 & 17.2 \\
\hline Assembly-4 & $10 / 25 / 2019$ & $16.7 / 3.9$ & 15.6 & 23.4 & 24.0 & 17.9 \\
\hline
\end{tabular}

A difference of between $5-16^{\circ}$ Celsius was observed between the kitchen configurations across all four parameters. Temperatures measured in the island and assembly kitchen configurations were highly similar in all WBGT parameters, with the assembly kitchen configuration measuring, on average, slightly higher temperatures than the island kitchen configuration (see Table 2). However, Kruskal-Wallis testing revealed that the differences between each configuration were not statistically significantly different (Table 3). 
Table 3. Kruskal-Wallis Results

\begin{tabular}{|c|c|c|c|c|}
\hline Temperatures & $\underline{\text { Wet }}$ & $\underline{\text { Dry }}$ & $\underline{\text { Globe }}$ & $\underline{\text { WBGTi }}$ \\
\hline$\underline{\text { K -Value }}$ & 5.32 & 3.57 & 2.96 & 3.60 \\
\hline$\underline{\text { P-Value }}$ & $0.069>0.05$ & $0.16>0.05$ & $0.22>0.05$ & $0.16>0.05$ \\
\hline
\end{tabular}

\section{Discussion}

This observational pilot study was performed to determine if temperatures in commercial kitchens reach levels that might result in employee heat stress, and to further determine if one kitchen configuration poses a higher risk of heat stress than another. Given that temperatures in 3 out of the 11 kitchens met or exceeded ACGIH guidelines, there is promising evidence that some commercial kitchens produce unsafe levels of heat.

Descriptive statistics showed that on average, the WBGTi for zone configurations are higher than other kitchen configurations. The average WBGTi of zone configurations were higher due to one reading of $89^{\circ} \mathrm{C}(\mathrm{dry}$ bulb) and $84.1^{\circ} \mathrm{C}$ (globe temperature); however, these temperatures are well within the limit of those measured by the WBGT (maximum temperature reading of $100^{\circ} \mathrm{C}$ ). Given that one other zone kitchen measured high temperatures, this is likely not an outlier but an extreme value due to the poor heat dispersal within that particular kitchen area.

The three configuration temperatures were found to be distributed similarly, suggesting that there is no significant difference in temperature by configuration type. However, given the trend of higher observed temperatures in zone kitchen types, further investigation of this question is warranted. Additional research with a larger sample size might reveal statistical significance indicating that zone configurations are less likely to adequately disperse heat.

These limitations in sample size were in large part due to difficulties in recruiting. Reasons stated for nonparticipation included anxiety and/or fear over instrumentation, with several restaurant staff asking if the instruments were radioactive. Other concerns focused on confusion over whether results from the sampling would be reported to OSHA. In many cases, researcher attempts to assuage these anxieties were unsuccessful. Often the greatest successes were found when speaking directly to the line cooks, as many of them expressed concern over high heat levels in their kitchens.

In spite of varying recruitment techniques, from an informative cover letter to ad hoc in-person recruitment, participation rates remained low. Kitchens that did not agree to participate in the study posed a non-response bias that may have skewed these results. It is possible that kitchens more willing to participate in the study were less concerned about heat, while others may have declined to participate in response to pre-existing concerns over temperature or concerns that they would be brought to light.

Conclusions and Recommendations

In spite of these limitations, this study offers preliminary insight into the heat-related stressors experienced by line cooks in commercial kitchens. Given the wide breadth of anecdotal evidence that commercial kitchens reach untenable temperatures, as well as the preliminary results from this study, this topic warrants additional investigation. Research that seeks to characterize and then eventually control heat stress may lead to reducing overall non-fatal occupational injuries and unnecessary heat strain by line cooks and other personnel in commercial kitchens. In particular, this study sought to examine kitchen configuration rather than personal protective equipment, shortened shifts, or alteration of work duties, all of which would likely be less than feasible in the high-stress restaurant industry. Arrangement of heat-generating instruments is an engineering control that would be relatively easy and inexpensive to implement, and therefore might be of greater interest to restaurant owners and managers than other options.

Future research in this area should seek first to reduce barriers to participation. Possible approaches include recruitment of line cooks specifically rather than restaurant managers, seeking corporate approval to conduct studies, or partnering with food inspections to assess temperature. This research may also be furthered by incorporating 
assessments of core body temperature (e.g., via an ingestible thermometer pill) among line cooks in order to determine how kitchen heat affects the body, as well as heat assessments that examine ventilation and cooling.

\section{References}

1. USDA. Food Industry Service, https://www.ers.usda.gov/topics/food-markets-prices/food-serviceindustry/market-segments/.

2. US Bureau of Labor Statistics. Occupational Employment Statistics, https://www.bls.gov/cps/cpsaat11.htm.

3. US Bureau of Labor Statistic. Labor Force Statistics from the Current Population Survey, https://www.bls.gov/oes/2018/may/oes352014.htm.

4. The Globe and Mail. A cycle of exploitation: How restaurants get cooks to work 12-hour days for minimum wage (or less), https://www.theglobeandmail.com/life/food-and-wine/food-trends/a-cycle-of-exploitation-howrestaurants-get-cooks-to-work-12-hour-days-for-minimum-wage-or-less/article26999168/ (accessed 20 March 2020).

5. Washington City Paper. Heat. Tempers. 13-hour Days. Line Cooks Function in an Intense and Brutal World., https://www.washingtoncitypaper.com/food/young-hungry/article/20982998/heat-tempers-13hour-days-linecooks-function-in-an-intense-and-brutal-world (accessed 20 March 2020).

6. Gaydos M, Bhatia R, Morales A, et al. Promoting Health and Safety in San Francisco's Chinatown Restaurants: Findings and Lessons Learned from a Pilot Observational Checklist. Public Health Reports 2011; 126: 62-69. DOI: $10.1177 / 00333549111260 S 311$.

7. Nabeel I and Alamgir H. Restaurant Inspection Reports as a Proxy Measure for Occupational Health and Safety: South Asian Restaurant Workers in New York City. Annals of global health 2018; 84: 495-499. DOI: 10.29024/aogh.2332.

8. Tsai JH-C and Salazar MK. Occupational Hazards and Risks Faced by Chinese Immigrant Restaurant Workers. Family \& Community Health 2007; 30: S71-S79. DOI: 10.1097/01.Fch.0000264882.73440.20.

9. POS Sector. The Complete Guide to Restaurant Kitchen Design, https://possector.com/hygiene/restaurantkitchen-design (accessed 3/6/2020).

10. Ghiselli R, Almanza BA and Ozaki S. Foodservice Design: Trends, Space Allocation, and Factors that Influence Kitchen Size. Foodservice Research International 1998; 10: 89-105. DOI: 10.1111/j.17454506.1998.tb00144.x.

11. Shimmura T, Fujii N and Kaihara T. Staff Motion Reduction at a Japanese Restaurant by Kitchen Layout Redesign after Kitchen Simulation. Procedia CIRP 2017; 62: 106-110. DOI: https://doi.org/10.1016/j.procir.2016.07.007.

12. Meloury J and Signal T. When the plate is full: Aggression among chefs. International Journal of Hospitality Management 2014; 41: 97-103. DOI: https://doi.org/10.1016/j.ijhm.2014.05.006.

13. Jeong BY. Cooking processes and occupational accidents in commercial restaurant kitchens. Safety Science 2015; 80: 87-93. DOI: https://doi.org/10.1016/j.ssci.2015.07.014.

14. Chamlee V. How Chefs and Link Cooks Beat the Heat. Eater. Vox Media, 2016.

15. Jayaraman S, Dropkin J, Siby S, et al. Dangerous Dining: Health and Safety in the New York City Restaurant Industry. Journal of Occupational and Environmental Medicine 2011; 53: 1418-1424. DOI: 10.1097/JOM.0b013e3182363b9f.

16. Alamgir H, Swinkels $\mathrm{H}, \mathrm{Yu} \mathrm{S}$, et al. Occupational injury among cooks and food service workers in the healthcare sector. Am J Ind Med 2007; 50: 528-535. DOI: 10.1002/ajim.20475.

17. Varghese BM, Hansen A, Bi P, et al. Are workers at risk of occupational injuries due to heat exposure? A comprehensive literature review. Safety Science 2018; 110: 380-392. DOI: https://doi.org/10.1016/j.ssci.2018.04.027. 
18. Ramphal L. Heat stress in the workplace. Proc (Bayl Univ Med Cent) 2000; 13: 349-350. DOI: 10.1080/08998280.2000.11927703.

19. Bouchama A and Knochel JP. Heat Stroke. New England Journal of Medicine 2002; 346: 1978-1988. DOI: 10.1056/NEJMra011089.

20. Gharibi V, Khanjani N, Heidari H, et al. The effect of heat stress on hematological parameters and oxidative stress among bakery workers. Toxicology and Industrial Health 2020; 36: 1-10. DOI: $10.1177 / 0748233719899824$.

21. Singh A, Kamal R, Mudiam MKR, et al. Heat and PAHs Emissions in Indoor Kitchen Air and Its Impact on Kidney Dysfunctions among Kitchen Workers in Lucknow, North India. PLOS ONE 2016; 11: e0148641. DOI: 10.1371/journal.pone.0148641.

22. CDC. Heat Stress, https://www.cdc.gov/niosh/topics/heatstress/default.html (accessed 20 March 2020).

23. Allen D. Restaurant Ventilation: Best Practices. FSR. 2014.

24. Websturantstore. https://www.webstaurantstore.com/article/11/restaurant-kitchen-layouts.html (accessed 20 March 2020).

25. OSHA. Estimating Work Rates or Loads, https://www.osha.gov/SLTC/heatillness/heat index/work rates loads.html (accessed Mar 25 2020).

26. OSHA. Heat Stress, https://www.osha.gov/dts/osta/otm/otm iii/otm iii 4.html (accessed March 62020 ).

27. Wet Bulb Globe Temperature (WBGT) Tool https://convergence.unc.edu/tools/wbgt/ (accessed March 62020 ).

28. U.S. Climate Data, https://www.usclimatedata.com/ (2020). 